\title{
QUANTIFICATION AND BIOREMEDIATION OF ENVIRONMENTAL SAMPLES BY DEVELOPING A NOVEL AND EFFICIENT METHOD
}

\author{
Mohammad Osama $^{a^{*}}$, Felicia Armstrong ${ }^{a}$, Peter Norris ${ }^{b}$, Habiba Tahira Hussain ${ }^{c}$ \\ ${ }^{a}$ Department of Geological and Environmental Sciences, Youngstown State University, Ohio 44555, US \\ ${ }^{b}$ Department of Chemistry, Youngstown State University, Ohio 44555, US \\ ${ }^{c}$ Department of Microbiology, Jawaharlal Nehru Medical College and Hospital, \\ Aligarh Muslim University, Aligarh 202002, India \\ *e-mail: osama.alig@gmail.com
}

\begin{abstract}
Pleurotus ostreatus, a white rot fungus, is capable of bioremediating a wide range of organic contaminants including Polycyclic Aromatic Hydrocarbons (PAHs). Ergosterol is produced by living fungal biomass and used as a measure of fungal biomass. The first part of this work deals with the extraction and quantification of PAHs from contaminated sediments by Lipid Extraction Method (LEM). The second part consists of the development of a novel extraction method, Ergosterol Extraction Method (EEM), quantification and bioremediation. The novelty of this method is the simultaneous extraction and quantification of two different types of compounds, sterol (ergosterol) and PAHs and is more efficient than LEM. EEM has been successful in extracting ergosterol from the fungus grown on barley in the concentration range of 17.5-39.94 $\mu \mathrm{g} \mathrm{g}^{-1}$ ergosterol and the PAHs are much more quantified in numbers and amounts as compared to LEM. In addition, cholesterol usually found in animals, has also been detected in the fungus, $P$. ostreatus at easily detectable levels, which is a noteworthy point.
\end{abstract}

Keywords: ergosterol, cholesterol, gas chromatography-mass spectrometry (GC-MS), sediments, polycyclic aromatic hydrocarbons (PAHs), ergosterol extraction method.

\section{Introduction}

\section{Mahoning River History}

Contamination of soils, sediments, ground water and air with toxic materials has become a major concern today. The Mahoning River has received industrial waste since early 1900's from the steel industry. The lower branch of the Mahoning River starts at Winona, Ohio, extending towards Leavittsburg, and continues to south-east through Girard, Youngstown, Struthers and Lowellville into Pennsylvania. The Mahoning River joins with the Shenango River to form the Beaver River, which empties into the Ohio River. It was significantly altered by the construction of numerous large reservoirs and low-head dams. The dams were constructed to provide a reservoir of cooling waters for the hot steel and machinery in the steel industries that used the river as an 'industrial sewer' [1] The sediment remained highly contaminated with PAHs and PCBs because of their tendency to bind to the sediment particles and their low solubility rates. When contaminants are introduced into aquatic environments, the sediments serve as a repository for the majority of these chemicals [2].

\section{Polycyclic Aromatic Hydrocarbons}

Polycyclic aromatic hydrocarbons (PAHs) are widespread contaminants in the environment and their fates in nature are of great environmental concern due to their potential toxicity, mutagenicity, teratogenicity and carcinogenicity $[3,4]$. Polycyclic aromatic hydrocarbons constitute a large and diverse class of organic compounds and are generally described as molecules which consist of two or more fused aromatic rings in various structural configurations [5]. The sources of PAHs include (i) mobile sources (e.g. cars, buses, trucks, ships and aircraft), (ii) industrial sources (e.g. power generation, steelworks, coke ovens, aluminium production, cement kilns, oil refining and waste incineration), (iii) domestic sources (e.g. combustion for heating and cooking especially solid fuel heaters using wood and coal), (iv) fires and smoke resulting from the burning of vegetation in agricultural processes, bushfires, grilling of food, or tobacco smoke [6-9]. Current research focuses on the effects of microbial biodegradation of PAHs composed of more than three rings. PAHs with more than three rings are often referred to as high-molecular-weight (HMW) PAHs [7,9]. Leaking storage containers on hazardous waste sites can release concentrated PAHs into soil and water making them especially dangerous to nursing infants living near hazardous waste sites [5,9]. PAH molecule stability and hydrophobicity are two primary factors which contribute to the persistence of HMW PAHs in the environment. Due to their lipophilic nature, PAHs have a high potential for biomagnifications through trophic transfers. Soil and sediment PAHs concentrations at contaminated and uncontaminated sites ranging from $1 \mu \mathrm{g} \mathrm{kg}^{-1}$ to over $300 \mathrm{~g} \mathrm{~kg}^{-1}$, have been reported [3,9]. A few PAHs are used in medicines, dyes, plastics, pesticides and road construction [3]. The potentially deleterious effects of PAHs on human health and their microbial biodegradation in the environmental system have prompted us to undertake this project. The very first goal of this research is to extract and measure the biodegradation of polycyclic aromatic hydrocarbons for the various samples collected from the sediments of Mahoning River using GC-MS by a Lipid Extraction procedure. A 
new method is developed, the Ergosterol Extraction Method, with the aim that it should be useful in the extraction of both PAHs as well as ergosterol. The importance of this study is to discover the bioremediation potentiality of Pleurotus ostreatus, a white rot fungus in wet, unique, historically contaminated river sediment. It is inoculated in the contaminated sediments of Mahoning River with subsequent analysis of the effect of ergosterol as an indicator for fungal biomass. In the wider sense the main objectives of this research can be outlined as (i) to develop a single extraction method, Ergosterol extraction Method (EEM), that should be useful in the extraction of both PAHs as well as ergosterol using GC-MS, (ii) to compare the two methods for the extraction of PAHs and analyze which one gives the most productive results, and (iii) analyze the extracted ergosterol by GC-MS so that we can detect the degradation of PAHs at different time intervals by Pleurotus ostreatus from the sediments of Mahoning River.

\section{Bioremediation by White Rot fungi (Pleurotus ostreotus)}

Bioremediation is a managed or spontaneous technique where microbiological processes (bacteria, fungi) are used to degrade or transform contaminants to less toxic or nontoxic forms. Low molecular weight PAHs are usually readily degraded, but high molecular weight PAHs of five or more rings resist extensive bacterial degradation in soil and sediments [10]. Fungi might offer some advantages over bacteria for remediation due to their rapid colonization of substrates and high tolerance of the toxin [11]. These fungi display an extracellular degradation system that is capable of cleaving lignin.

Steroids

Sterols are essential structural and regulatory components of eukaryotic cell membranes. Ergosterol, the end product of the biosynthetic pathways and the main sterol in yeast and other fungi, is responsible for structural membrane features, such as fluidity and permeability similar to the way cholesterol is in mammalian cells [12]. Ergosterol is considered as the principal sterol of fungi and it plays an important role as a cell membrane component. Therefore, it has been proposed as a global indicator of mycological quality of foods and feeds.

\section{Experimental}

Standard of chemical compounds used was performed as $10.0,20.0,30.0,40.0$, and $50.0 \mu \mathrm{g} / \mathrm{mL}$ concentrations of the PAH mix, $20 \mu \mathrm{L}$ of internal standard, and $50 \mu \mathrm{L}$ of surrogate solution were added and the volume adjusted to 1.0 $\mathrm{mL}$ with hexane.

\section{Part 1: Biodegradation of PAHs \\ Sample Collection}

Sediment samples were collected from the shoreline of the Mahoning River in Lowellville, Ohio and stored at $4^{\circ} \mathrm{C}$ until use. Each sediment sample was analyzed for PAHs content using both lipid extraction and ergosterol extraction techniques to track the extraction efficiencies.

\section{Fungal Growth}

The white-rot culture was grown by on white-rot selective potato dextrose agar (PDA) plates [20]. The inoculated selective plates were placed in incubators at $25^{\circ} \mathrm{C}$ for $72-120 \mathrm{~h}$. Cores of the plates were taken and placed into sterile $250 \mathrm{~mL}$ Erlenmeyer flasks containing $125 \mathrm{~mL}$ of Potato Dextrose broth (Sigma). Broths were placed on a shaker at $250 \mathrm{rpm}$ for $48-72 \mathrm{~h}$ at room temperature. After growth of inocula in $125 \mathrm{~mL}$ of Potato Dextrose broth, $500 \mathrm{~mL}$ of grain was placed into spawn bag (Fungi Perfecti LLC) with $150 \mathrm{~mL}$ of deionized water. The spawn bag containing the grain and water mixture was sealed using an impulse sealer and autoclaved at $121{ }^{\circ} \mathrm{C}$. Once autoclaved, the spawn bag was then inoculated with $125 \mathrm{~mL}$ of the Potato Dextrose broth containing the $P$. ostreatus inocula. Spawn bags were then placed in a $25^{\circ} \mathrm{C}$ incubator for $72-120 \mathrm{~h}$.

\section{Sediment Incubation Set-up}

One litre of the PAH contaminated Mahoning River sediment was transferred into $2 \mathrm{~L}$ glass containers ("fish bowls"). Eight experimental treatments were tested in triplicate in the laboratory during a 6 weeks period. The first treatment contained only sediment which was used as control. Treatment sediment was amended with sawdust (60\% by volume), augmented with Pleurotus ostreatus ( $10 \%$ by volume) in the treatments and $10 \%$ by volume of inoculated grain was added to each bowl (containing sediment samples) as substrates for fungal growth. The second treatment (by volume) was $30 \%$ sediment with $60 \%$ sawdust augmented with Pleurotus ostreatus (10\% by volume) and $10 \%$ of the inoculated grain as substrates for fungal growth was added to each bowl. To the treatments with sawdust (which provides carbon and nutrients to fungi), fungi (Pleurotus ostreatus) and additional nitrogen source (10\% by volume) was added to stimulate fungal growth. A treatment free sediment sample was taken as control. The nitrogen sources included spawnmate, urea, peptone and tryptophan. Contents of the bowl were mixed to create a homogenous mixture. A glass petri dish filled with sterile water was suspended inside the glass bowl to keep the moisture content constant. 
Incubation bowls were covered first with plastic wrap then aluminium foil and placed in an incubator at $25^{\circ} \mathrm{C}$. Initially, seven treatments were tested at time zero in July 2008. PAH extractions were done from these samples as a test of the lipid extraction method. The first controls contained sediment, saw dust $(600 \mathrm{~mL})$, grain $(100 \mathrm{~mL})$ and fungi $(100 \mathrm{~mL})$. In October 2008, eight more treatments were prepared and PAH extractions of each treatment were done at two different times: $0 \mathrm{~d}$ and $21 \mathrm{~d}$.

\section{Lipid Extraction Method}

PAHs were extracted using a modified lipid extraction method [13] from the contaminated sediments of the Mahoning River. A mixture of dichloromethane (DCM), methanol, phosphate buffer ( $\mathrm{pH} 7.4$ ) and a surrogate solution were added to the samples, mixed well and extracted. The organic phase (DCM) containing PAHs was collected and purified over sodium sulfate columns. The sample was further concentrated by evaporating the solvent.

\section{Part 2: Ergosterol Extraction Method}

\section{Steroids Extraction Procedure:}

Much work is done for the extraction of PAHs and ergosterol separately using high performance liquid chromatography (HPLC) which can be time consuming and create higher amounts of waste [13-20]. Using a single extraction method to extract PAHs and ergosterol together is both less time consuming and produces less waste. Gas chromatography-mass spectrometry (GC-MS) is used for analysis instead of HPLC because it is more efficient and accurate due to its high degree of sensitivity and specificity. Sediment and reference ergosterol extraction and analysis were done using a method modified from the protocol described by Brodie et al. [21] with ethanol used as the extraction of alcohol because of its greater extraction efficiency reported by Padgett et al. [22]. The reference standard of sterols (ergosterol and cholesterol 98\% purity, Sigma- Aldrich) was prepared in dichloromethane (DCM). During the extraction procedure of samples, $\mathrm{KOH}(1.50 \mathrm{M})$ in $96 \%$ ethanol was used for the saponification process. This caused de-esterification of the complexed ergosterol to its free form and to facilitate its detection. All extractions of sterol (ergosterol and cholesterol) were done in triplicate. The control mixtures were a combination of Sediment + Sawdust + Fungi grown on barley. The sample mixtures were fungi grown on PDA and barley and then mixed with sediment. The fungi were cultivated on barley in a bio-bag for approximately 3-weeks prior to sampling. The pure fungi were grown on PDA as described previously. Sediment was collected from Lowellville, Ohio, in September 2008. Fungi and sediment mixtures (controls and samples) were not incubated together; these were mixed just prior to sampling and analysis. A total of twenty-one treatments (control mixture and sample mixtures) were done in triplicate. Acetylation was done for samples containing pure fungi and samples containing sediment.

This helps to separate the sterols from other contaminants such as PAHs. GC requires that the compound should be in the gaseous phase, therefore to extract ergosterol (m.p. $160^{\circ} \mathrm{C}$, b.p. $250{ }^{\circ} \mathrm{C}$ ), its melting point should be lowered. Therefore, by doing acetylation its melting point is lowered and more easily detected on GC-MS. Another advantage of acetylation is that the original compound can be regenerated by hydrolysis.

\section{Purification}

Both the samples from the lipid extraction procedure and modified protocol from Brodie et al. [21] for sterols were concentrated and passed over silica gel columns. Any unwanted sediment waste adsorbs onto the activated silica, thus purifying the samples. The samples were further purified twice over the aminopropyl columns and analyzed by GCMS after the internal standard was added (for PAHs analysis only).

\section{Analysis of PAHs and steroids}

Commercial ergosterol and cholesterol were analysed by GC-MS as standard references. When the samples collected from the Ergosterol Extraction Method was analyzed using GC-MS, 16 PAHs were detected. All analyses were performed on a Hewlett Packard 5890 Gas Chromatograph/ 5989A Mass Spectrometer equipped with a DB-5 column (30 m, $0.32 \mathrm{~mm}$ ID, and a HP 6890 Series Injector). The injector and the detector temperatures were set at $250{ }^{\circ} \mathrm{C}$ and $300^{\circ} \mathrm{C}$ respectively. The oven temperature was held at $45^{\circ} \mathrm{C}$ for $2 \mathrm{~min}$, and then ramped at $20^{\circ} \mathrm{C}$ per minute to $310^{\circ} \mathrm{C}$. The final temperature was held for $5.5 \mathrm{~min}$.

\section{Results and discussion}

\section{Part 1: Bioremediation and quantification of PAHs}

The data are shown (Tables 2, 3 and 4) as a comparison of degradation patterns of low and high molecular weights PAHs ( $\mu \mathrm{g}$ PAHs g ${ }^{-1}$ sediment dry weight).

\section{PAHs analyses}

Of the detected PAHs, fluoranthene was of the highest concentration with $85.10 \mu \mathrm{g} \mathrm{g}^{-1} \mathrm{dry}$ weight, followed by pyrene with $69.14 \mu \mathrm{g} \mathrm{g}^{-1}$ dry weight (Table 1). 
Four treatments were done: (1) Control (2) Sawdust (3) Sawdust + fungi and (4) Sawdust + fungi + nitrogen. By the end of the experiment $(21 d)$, nine of the eleven PAHs were detected which showed degradation in the sample with Pleurotus ostreatus + sawdust. The total PAH concentration was reduced by $58.6 \%$ from $253 \mu \mathrm{g} \mathrm{g}^{-1}$ of dry weight on day 0 to $173 \mu \mathrm{g} \mathrm{g}^{-1}$ on day 21 .

When extractions were carried out in triplicate by the lipid extraction method for PAHs, only seven PAHs were detected, at time zero (Table 2) and only nine PAHs were detected, at time $21 d$ (Table 3) by GC-MS. The quantity of low molecular weight PAHs and high molecular weight PAHs varies from sample to sample when analyzed by GC-MS at time 0 and $21 d$.

Table 1

PAHs detected in Mahoning river sediment by lipid extraction procedure.

\begin{tabular}{|c|c|c|c|}
\hline No. & PAHs & Retention Time & $\begin{array}{c}\text { Concentration } \boldsymbol{\mu g} \mathbf{g}^{-1} \mathbf{\text { dry }} \\
\text { weight }\end{array}$ \\
\hline 1 & Naphthalene & 9.05 & 13.03 \\
\hline 2 & Acenaphthylene & 11.26 & 1.23 \\
\hline 3 & Acenaphthene & 11.49 & 11.76 \\
\hline 4 & Fluorene & 12.19 & 39.37 \\
\hline 5 & Phenanthrene & 13.55 & 46.64 \\
\hline 6 & Anthracene & 13.55 & 85.10 \\
\hline 7 & Fluoranthene & 15.20 & 69.14 \\
\hline 8 & Pyrene & 15.53 & 17.48 \\
\hline 9 & $1,2-B e n z a n t h r a c e n e$ & 17.42 & 15.10 \\
\hline 10 & Chrysene & 17.42 & 40.19 \\
\hline 11 & $2,3-$ Benzfluoranthene & 19.79 & N.D \\
\hline 12 & 3,4-Benzopyrene & 0 & N.D \\
\hline 13 & $1,2: 5,6-$ Dibenzanthracene & 0 & N.D \\
\hline 14 & Indeno(1,2,3-cd)pyrene & 0 & N.D \\
\hline 15 & $1,12-B e n z o p e r y l e n e$ & 0 & \\
\hline
\end{tabular}

Table 2

PAHs detected in Mahoning river sediment by lipid extraction procedure at time 0 days.

\begin{tabular}{|c|c|c|c|}
\hline No. & PAHs & Retention Time & $\begin{array}{c}\text { Concentration } \boldsymbol{\mu g} \mathbf{g}^{-1} \mathbf{d r y} \\
\text { weight }\end{array}$ \\
\hline 1 & Naphthalene & 9.05 & N.D \\
\hline 2 & Acenaphthylene & 11.26 & N.D \\
\hline 3 & Acenaphthene & 11.49 & N.D \\
\hline 4 & Fluorene & 12.19 & 15.51 \\
\hline 5 & Phenanthrene & 13.55 & 18.92 \\
\hline 6 & Anthracene & 13.55 & 39.63 \\
\hline 7 & Fluoranthene & 15.20 & 26.37 \\
\hline 8 & Pyrene & 15.53 & N.D \\
\hline 9 & $1,2-B e n z a n t h r a c e n e$ & 17.42 & 19.89 \\
\hline 10 & Chrysene & 17.42 & 17.55 \\
\hline 11 & $2,3-B e n z f l u o r a n t h e n e$ & 19.79 & 14.11 \\
\hline 12 & $3,4-B e n z o p y r e n e$ & 0 & N.D \\
\hline 13 & $1,2: 5,6-$ Dibenzanthracene & 0 & N.D \\
\hline 14 & Indeno(1,2,3-cd)pyrene & 0 & N.D \\
\hline 15 & $1,12-$ Benzoperylene & 0 & \\
\hline
\end{tabular}


PAHs detected in Mahoning river sediment by lipid extraction procedure at time 21 days.

\begin{tabular}{|c|c|c|c|}
\hline No. & PAHs & Retention Time & $\begin{array}{c}\text { Concentration } \boldsymbol{\mu g ~ g}^{-1} \mathbf{~ d r y ~} \\
\text { weight }\end{array}$ \\
\hline 1 & Naphthalene & 9.05 & N.D \\
\hline 2 & Acenaphthylene & 11.26 & 0.48 \\
\hline 3 & Acenaphthene & 11.49 & N.D \\
\hline 4 & Fluorene & 12.19 & 8.65 \\
\hline 5 & Phenanthrene & 13.55 & 12.09 \\
\hline 6 & Anthracene & 13.55 & 24.72 \\
\hline 7 & Fluoranthene & 15.20 & 19.23 \\
\hline 8 & Pyrene & 15.53 & 3.65 \\
\hline 9 & 1,2-Benzanthracene & 17.42 & 8.32 \\
\hline 10 & Chrysene & 17.42 & 5.92 \\
\hline 11 & $2,3-$ Benzfluoranthene & 19.79 & 13.78 \\
\hline 12 & $3,4-$ Benzopyrene & 0 & N.D \\
\hline 13 & $1,2: 5,6-$ Dibenzanthracene & 0 & N.D \\
\hline 14 & Indeno(1,2,3-cd)pyrene & 0 & N.D \\
\hline 15 & $1,12-$ Benzoperylene & 0 & N.D \\
\hline
\end{tabular}

N.D - Not detected

\section{Part 2: Bioremediation and quantification of PAHs and quantification of ergosterol}

Sixteen PAHs were extracted using the modified ergosterol extraction method (Table 4), six of them being low molecular weight PAHs, namely naphthalene; acenaphthylene; acenaphthene; fluorine; phenanthrene and anthracene. Ten high molecular weight PAHs were detected which include fluoranthene; 1,2-Benzanthracene; pyrene; chrysene; 2,3-Benzfluoranthene; 11,12-Benzofluoranthene; 3,4-Benzopyrene; 1,2:5,6-Dibenzanthracene; Indeno(1,2,3-cd)pyrene and 1,12-Benzoperylene. The quantity of PAHs extracted from this method is much more than that extracted by the lipid extraction method (Table 2). The PAHs were extracted by the modified ergosterol extraction method done in triplicate from the samples having the treatment: fungi grown on barley $(0.6207 \mathrm{~g})+$ sediment $(0.6199 \mathrm{~g})$, fungi grown on barley $(0.6143 \mathrm{~g})+$ sediment $(1.1886 \mathrm{~g})$ and fungi grown on barley $(0.6327 \mathrm{~g})+$ sediment $(0.5743 \mathrm{~g})$. The extractions from these samples were analyzed by GC-MS without acetylation.

Table 4

Average PAHs detected in Mahoning river sediment (Controls) by Ergosterol Extraction Method.

\begin{tabular}{|c|c|c|c|}
\hline No. & PAHs & RetentionTime & $\begin{array}{c}\text { Concentration } \boldsymbol{\mu g} \mathbf{g}^{-1} \mathbf{d r y} \\
\text { weight }\end{array}$ \\
\hline 1 & Naphthalene & 9.71 & 7.36 \\
\hline 2 & Acenaphthylene & 11.06 & 53.72 \\
\hline 3 & Acenaphthene & 11.21 & 26.22 \\
\hline 4 & Fluorene & 11.60 & 43.51 \\
\hline 5 & Phenanthrene & 12.43 & 235.76 \\
\hline 6 & Anthracene & 12.46 & 183.12 \\
\hline 7 & Fluoranthene & 13.43 & 858.76 \\
\hline 8 & Pyrene & 13.63 & 385.04 \\
\hline 9 & $1,2-B e n z a n t h r a c e n e$ & 14.66 & 224.34 \\
\hline 10 & Chrysene & 14.70 & 375.29 \\
\hline 11 & $2,3-$ Benzfluoranthene & 15.83 & 328.76 \\
\hline 12 & $11,12-B e n z o f l u o r a n t h e n e$ & 15.83 & 336.57 \\
\hline 13 & 3,4-Benzopyrene & 16.17 & 68.71 \\
\hline 14 & $1,2: 5,6-$ Dibenzanthracene & 18.05 & 42.63 \\
\hline 15 & Indeno(1,2,3-cd)pyrene & 18.06 & 140.90 \\
\hline 16 & $1,12-$ Benzoperylene & 18.58 & \\
\hline
\end{tabular}


The concentrations of PAHs in the contaminated sediment samples were calculated (Eq. (1)).

$$
(D \times X) / M=C
$$

Where:

$D=$ Amount of DCM with suspended PAHs extracted from the sample, $\mathrm{mL}$;

$X=$ Concentration of the sample given by GC-MS, $\mu \mathrm{g} \mathrm{mL}^{-1}$;

$M=$ Mass of the sample before extraction, $\mathrm{g}$;

$C=$ Concentration of PAHs in the sample, $\mu \mathrm{g} \mathrm{g}^{-1}$.

The ergosterol was extracted and analyzed by GC-MS from the samples of pure fungi grown on PDA done in triplicate: pure fungi $(0.5325 \mathrm{~g})$, pure fungi $(0.5247 \mathrm{~g})$ and pure fungi $(0.5225 \mathrm{~g})$ (Figure 1a). The peak was detected at 397 a.m.u. which corresponds with ergosterol (Figure 1b). Acetylation of ergosterol was done after extraction of ergosterol.

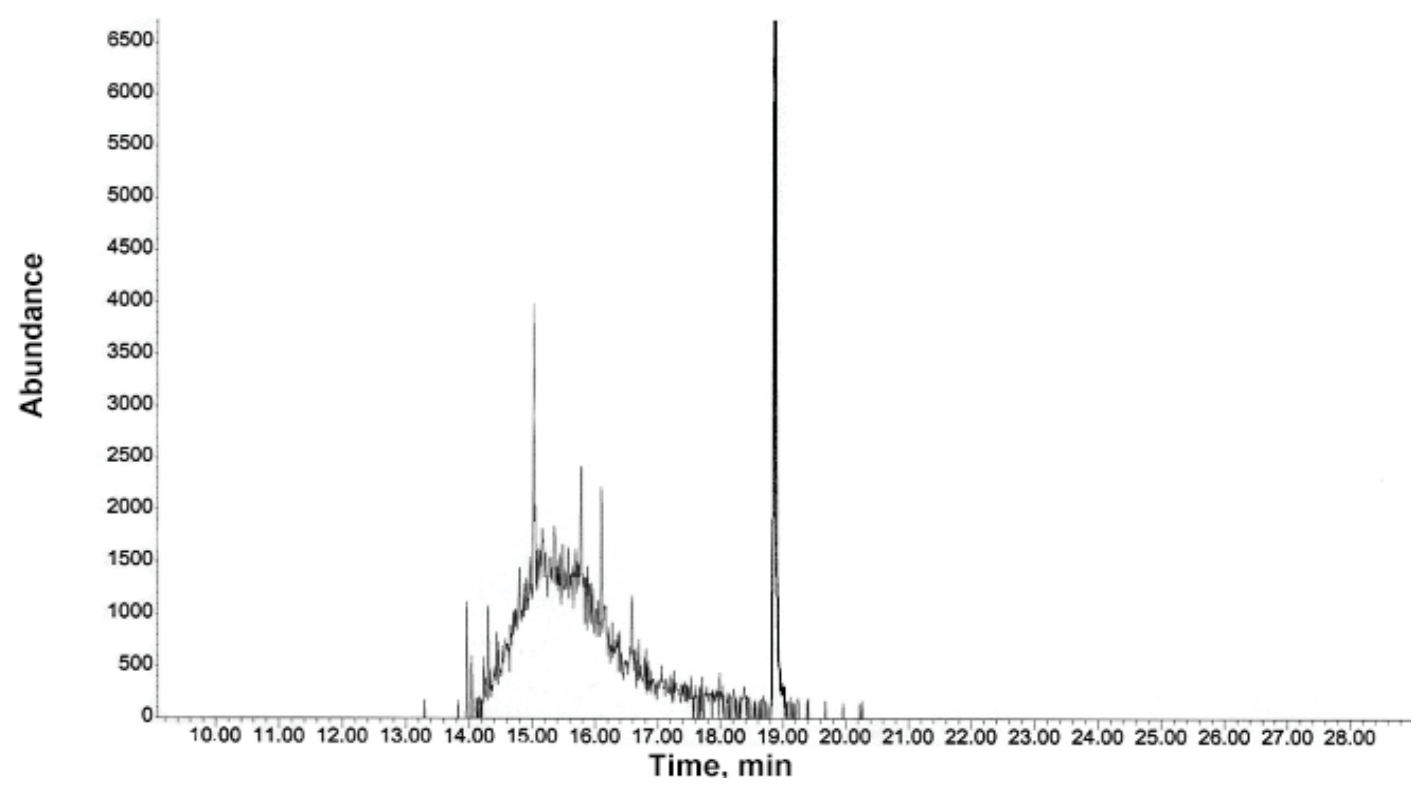

Figure 1a. MS chromatogram of ergosterol by EEM from fungi grown on potato dextrose agar, $\mathrm{m} / \mathbf{z} 396$.

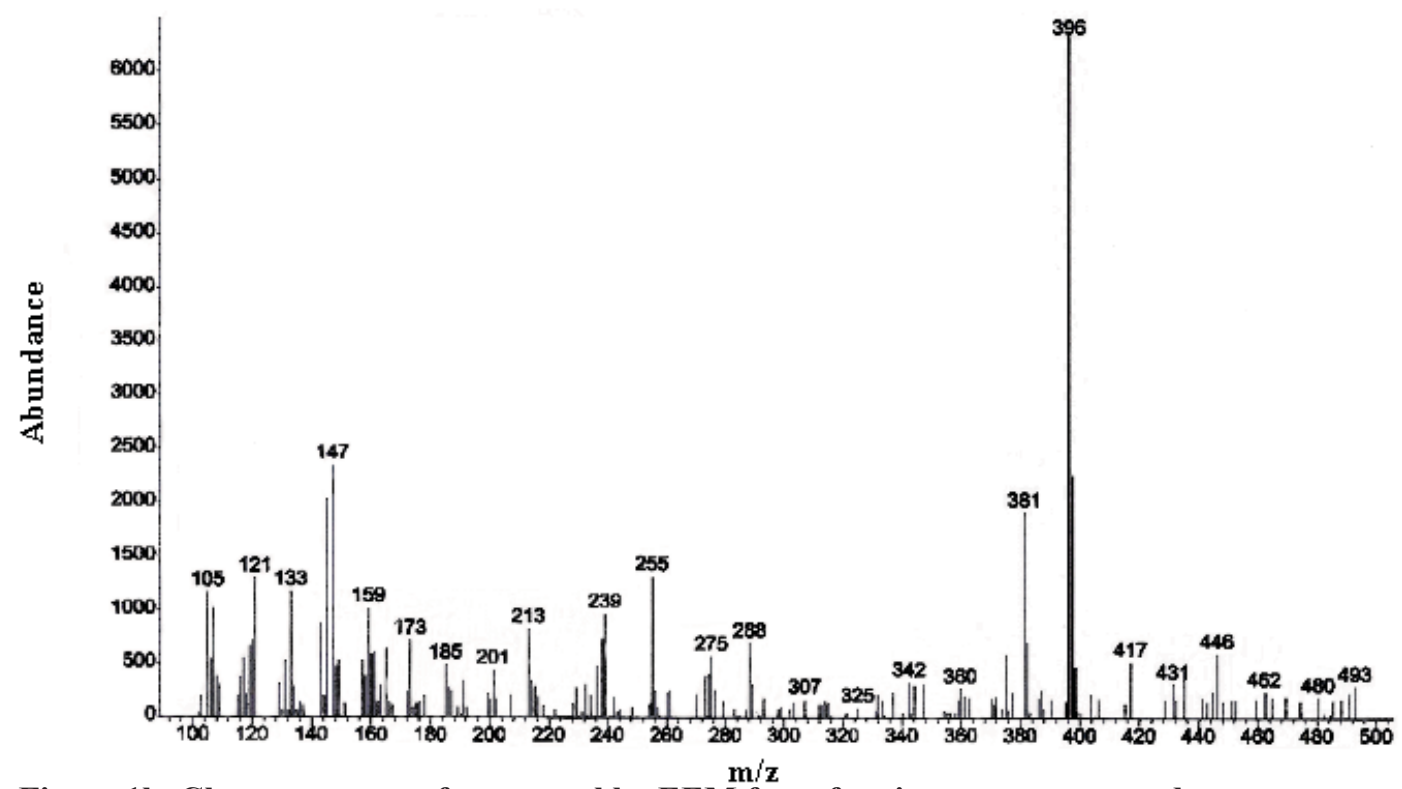

Figure 1b. Chromatogram of ergosterol by EEM from fungi grown on potato dextrose agar. 
The extraction of samples done in triplicate taking pure fungi grown on PDA and sediment added separately: pure fungi $(0.5283 \mathrm{~g})+$ sediment $(0.5880 \mathrm{~g})$, pure fungi $(0.54480 \mathrm{~g})+$ sediment $(0.5132 \mathrm{~g})$ (Figures 2,3 and 4$)$ and pure fungi $(0.6184 \mathrm{~g})+$ sediment $(0.5368 \mathrm{~g})$. After the extraction, cholesterol and PAHs were detected from GC-MS, this is the first report for the occurrence of cholesterol (Figures 2 and 3). Cholesterol was seen after acetylation of sterol by GC-MS (Figure 3).

The extraction of pure fungi grown on PDA was done without acetylation and analyzed by GC-MS. Cholesterol and ergosterol were detected in high amounts with high intensity of peaks being observed for both sterols (Figures 3 and 4). The significant result is that cholesterol is usually found in animals but here it was detected in fungus $P$. ostreatus for the first time in good amount.

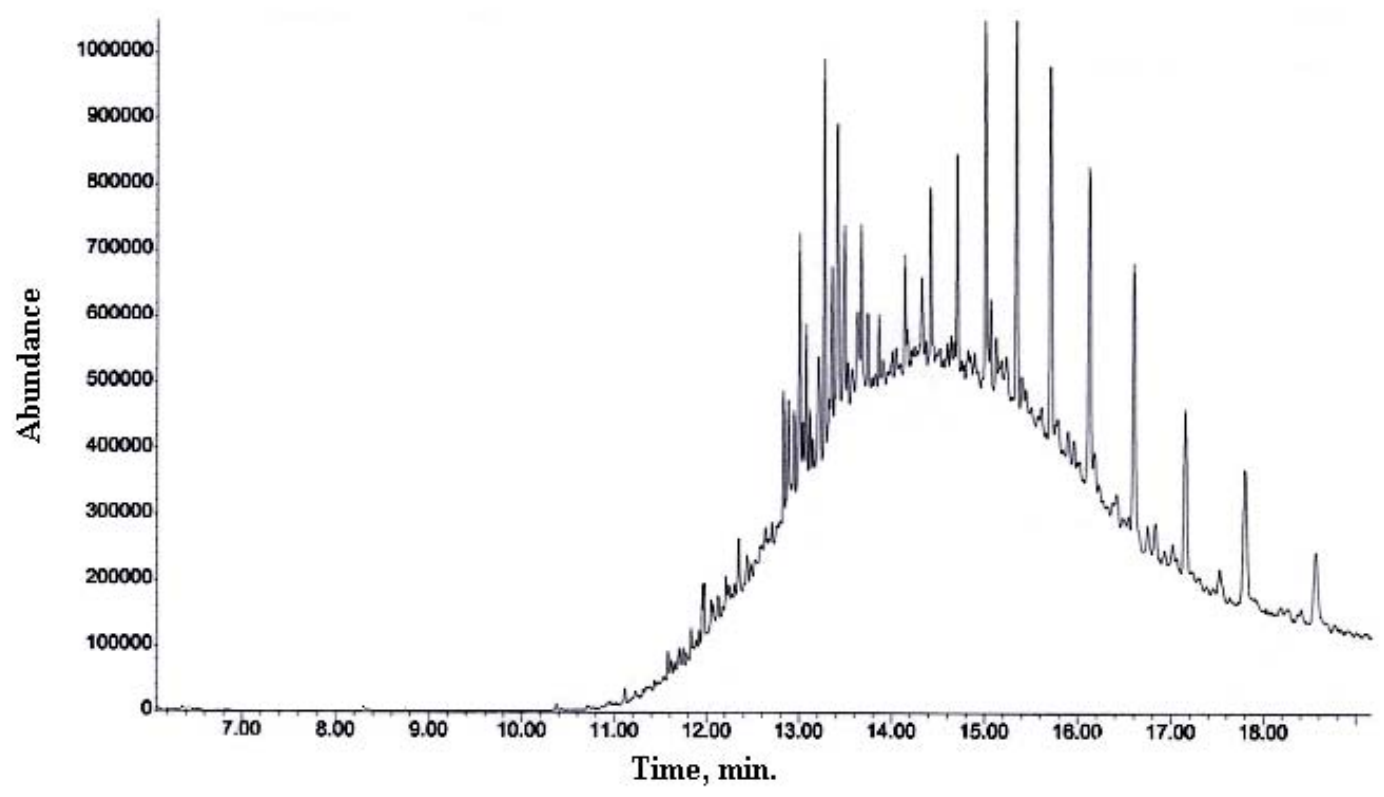

Figure 2a. MS chromatogram of PAHs by EEM from pure fungi plus sediment, $\mathrm{m} / \mathrm{z}$ 105, 119, 128, 145, 159, 171, 183, 197, 251, 270, 284, 302.

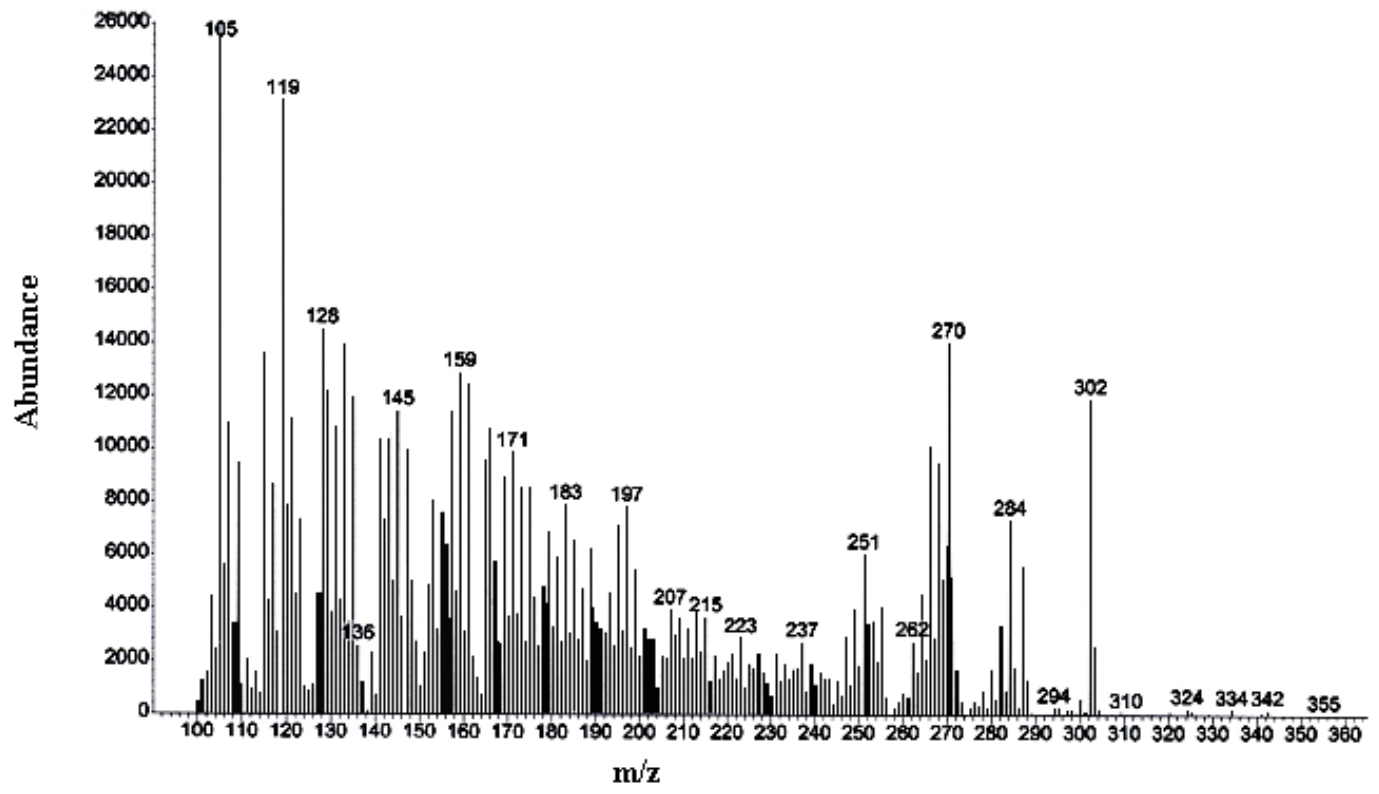

Figure 2b. Chromatogram of PAHs by EEM from pure fungi plus sediment. 


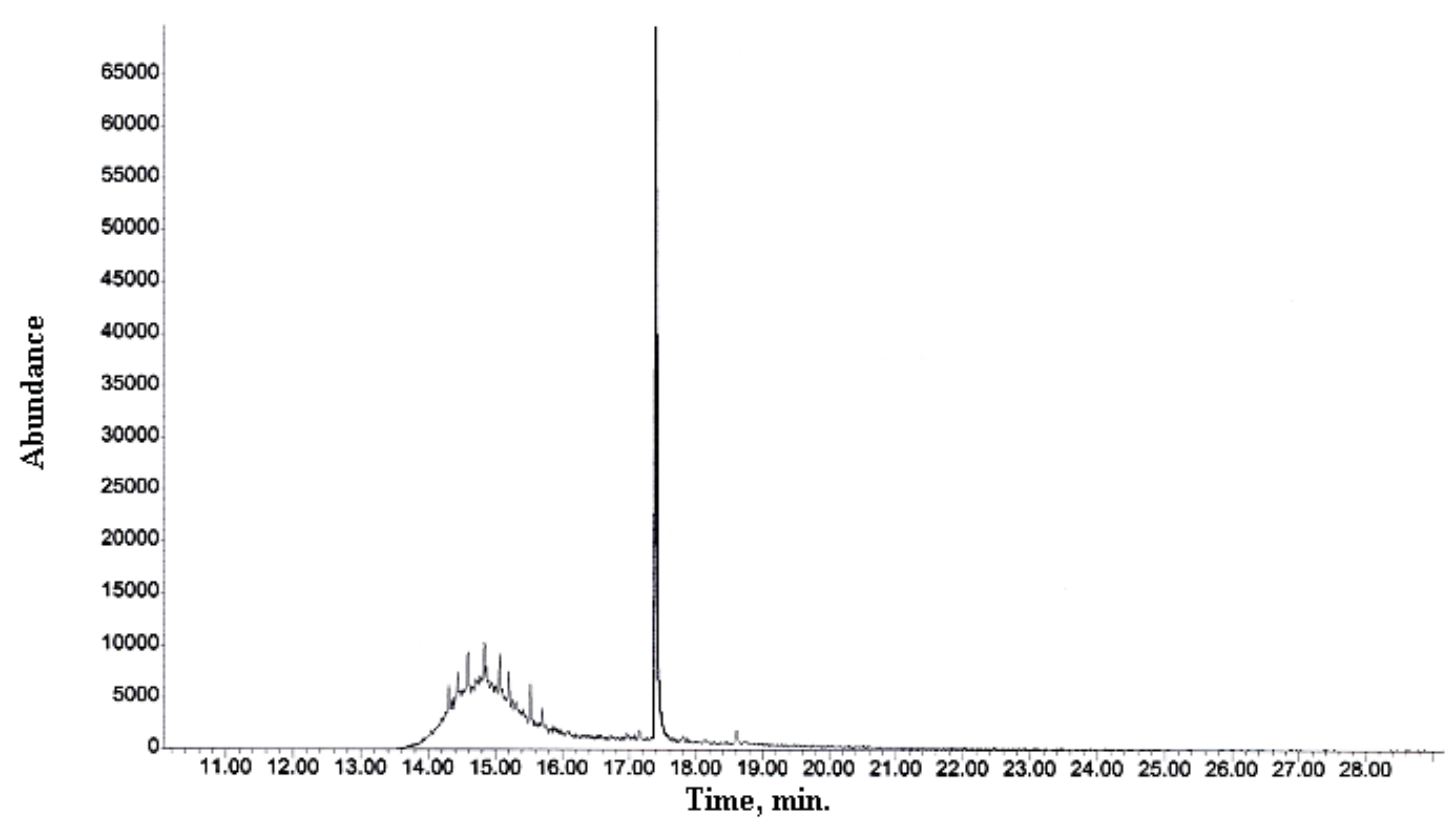

Figure 3a. MS chromatogram of cholesterol by EEM from pure fungi plus sediment, m/z 368 .

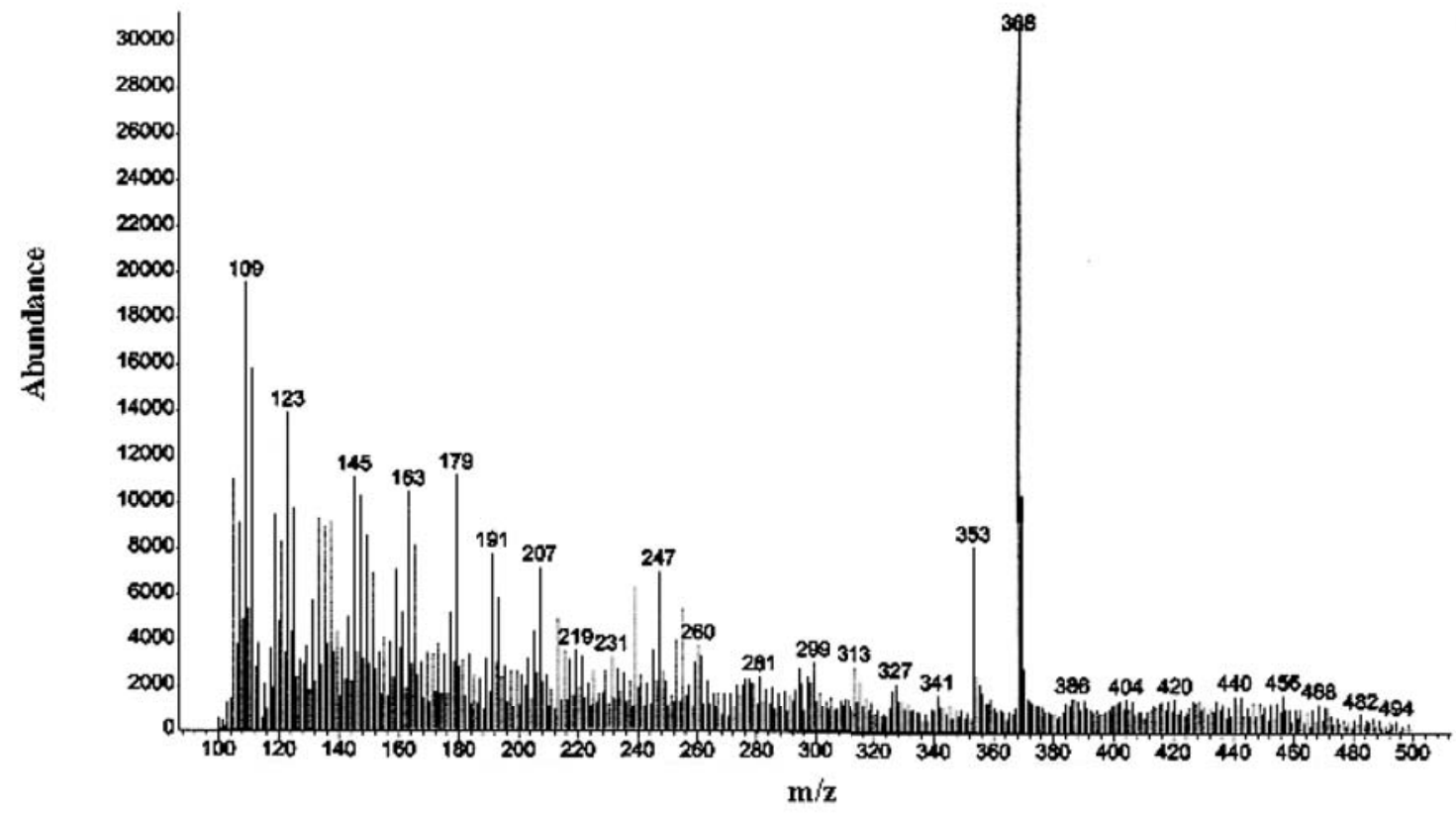

Figure 3b. Chromatogram of cholesterol by EEM from pure fungi plus sediment. 


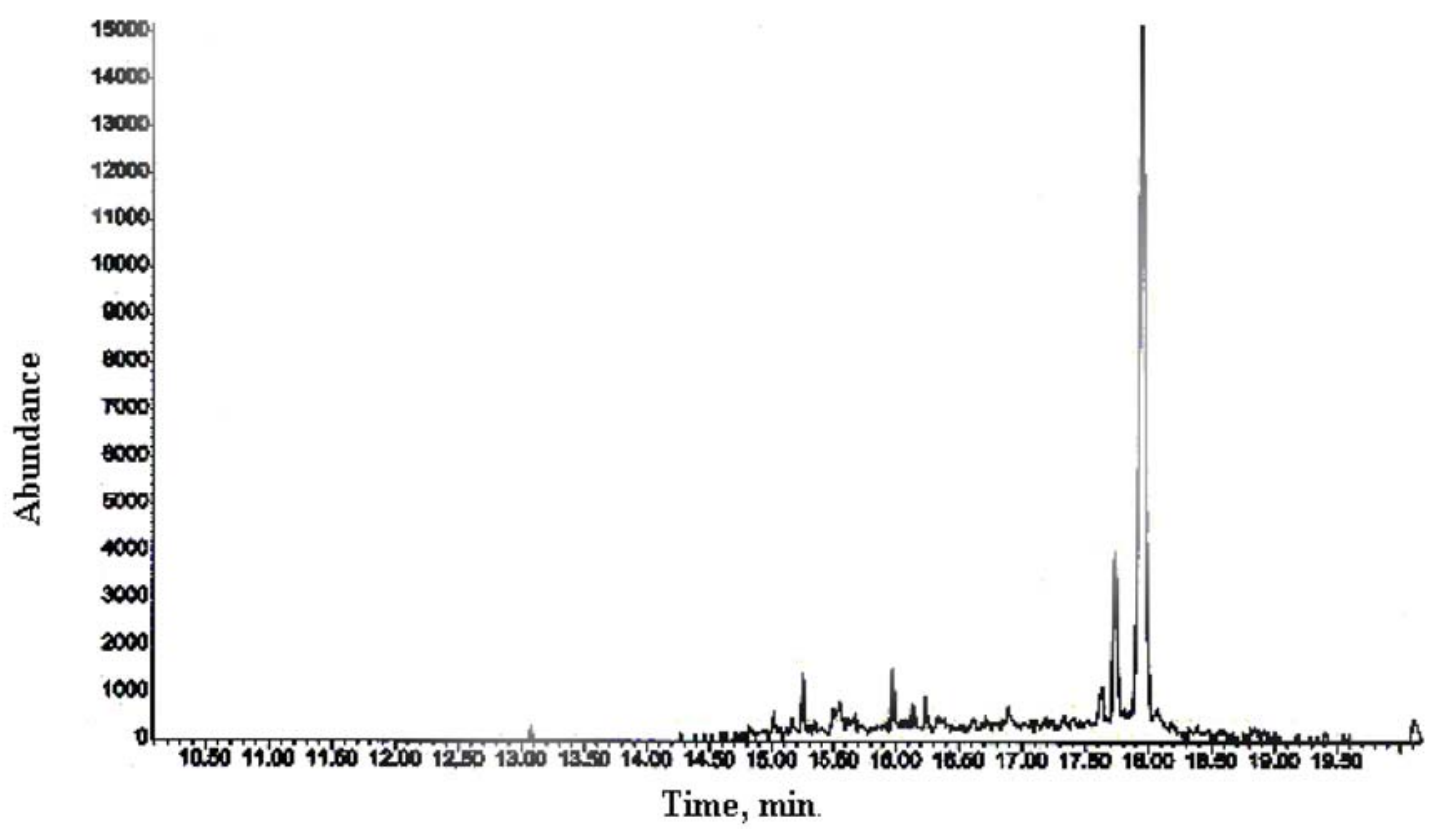

Figure 4a. MS chromatogram of ergosterol by EEM from the fungi $P$. ostreatus grown on potato dextrose agar, $\mathrm{m} / \mathbf{z} 378$.

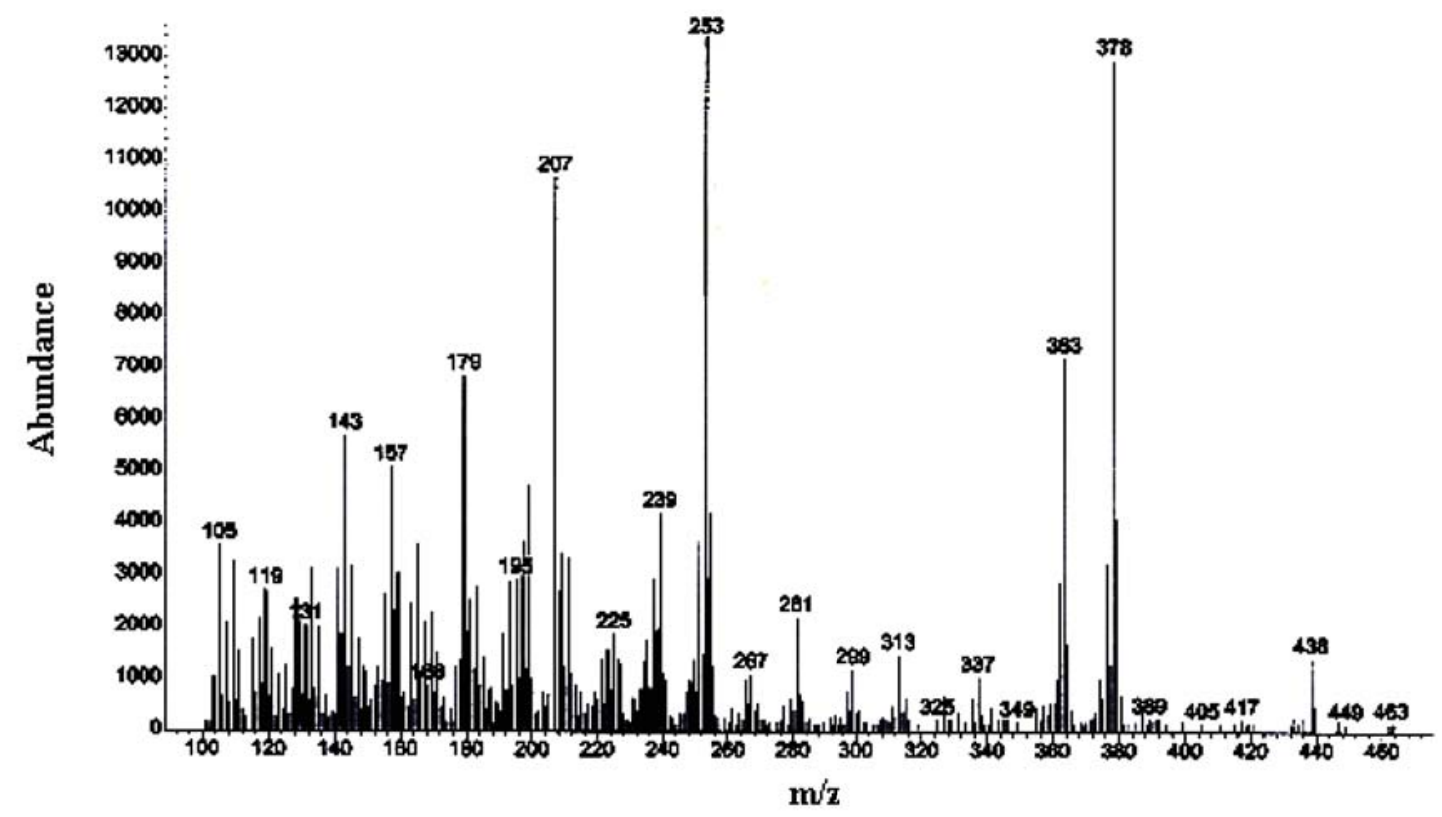

Figure 4b. Chromatogram of ergosterol extracted by EEM from the fungi $P$. ostreatus grown on potato dextrose agar.

The detection of cholesterol and ergosterol in fungi by GC-MS was analyzed from the peaks of standard reference spectra of commercial ergosterol and cholesterol. The cholesterol and ergosterol in fungi were also confirmed by the standard reference peaks of acetylated cholesterol and ergosterol, which were acetylated from the commercial cholesterol and ergosterol.

The detection of ergosterol by GC-MS from the samples done in triplicate and the amounts of ergosterol per

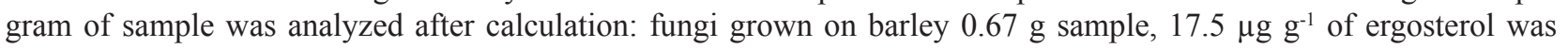

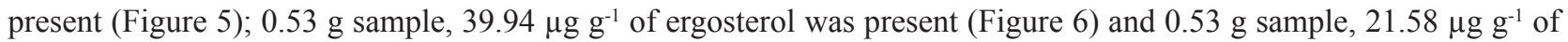
ergosterol was present (Figure 7). 


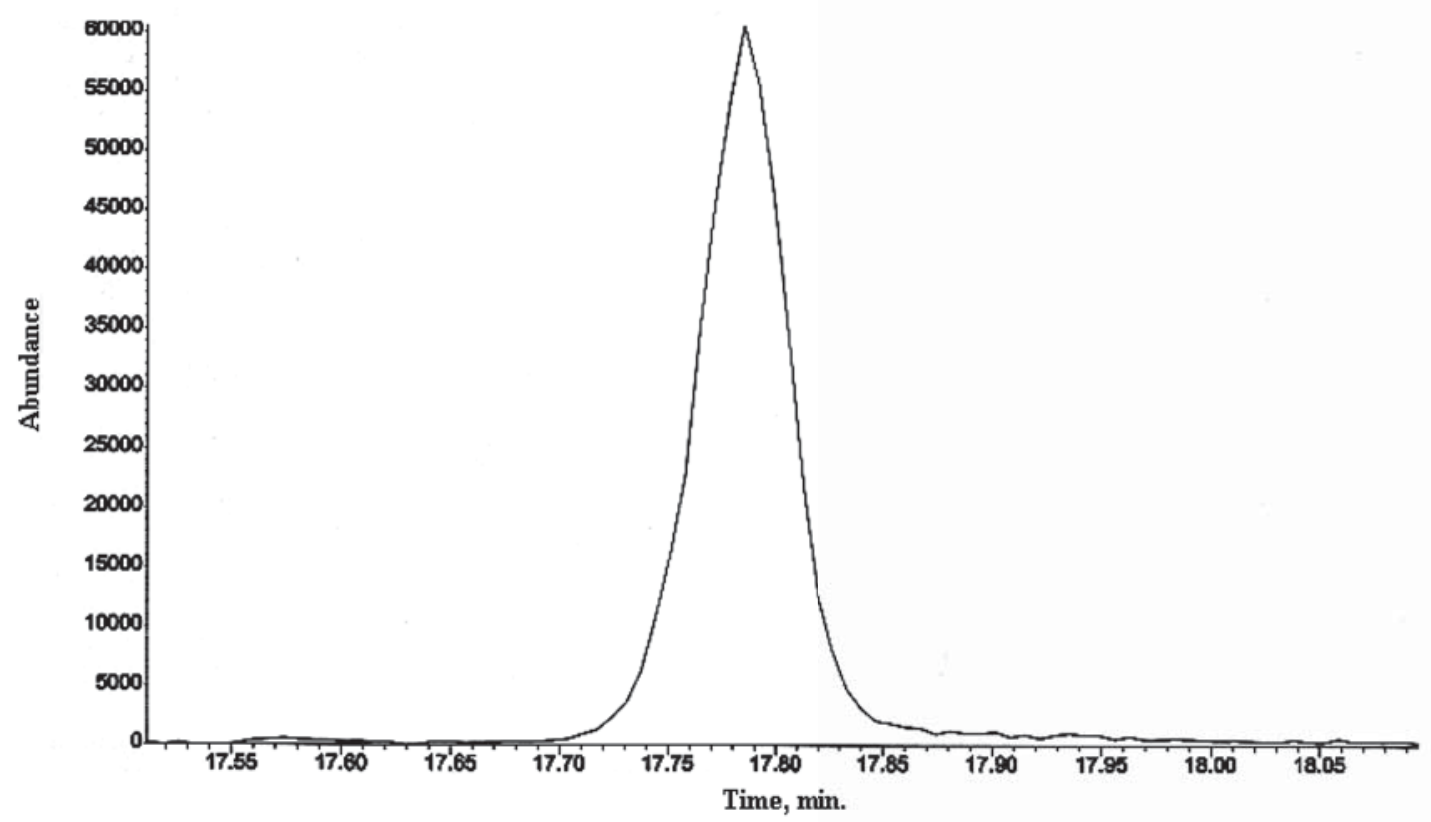

Figure 5a. MS chromatogram of ergosterol by EEM in P. ostreatus grown on barley is at $\mathbf{m} / \mathbf{z} 396$.

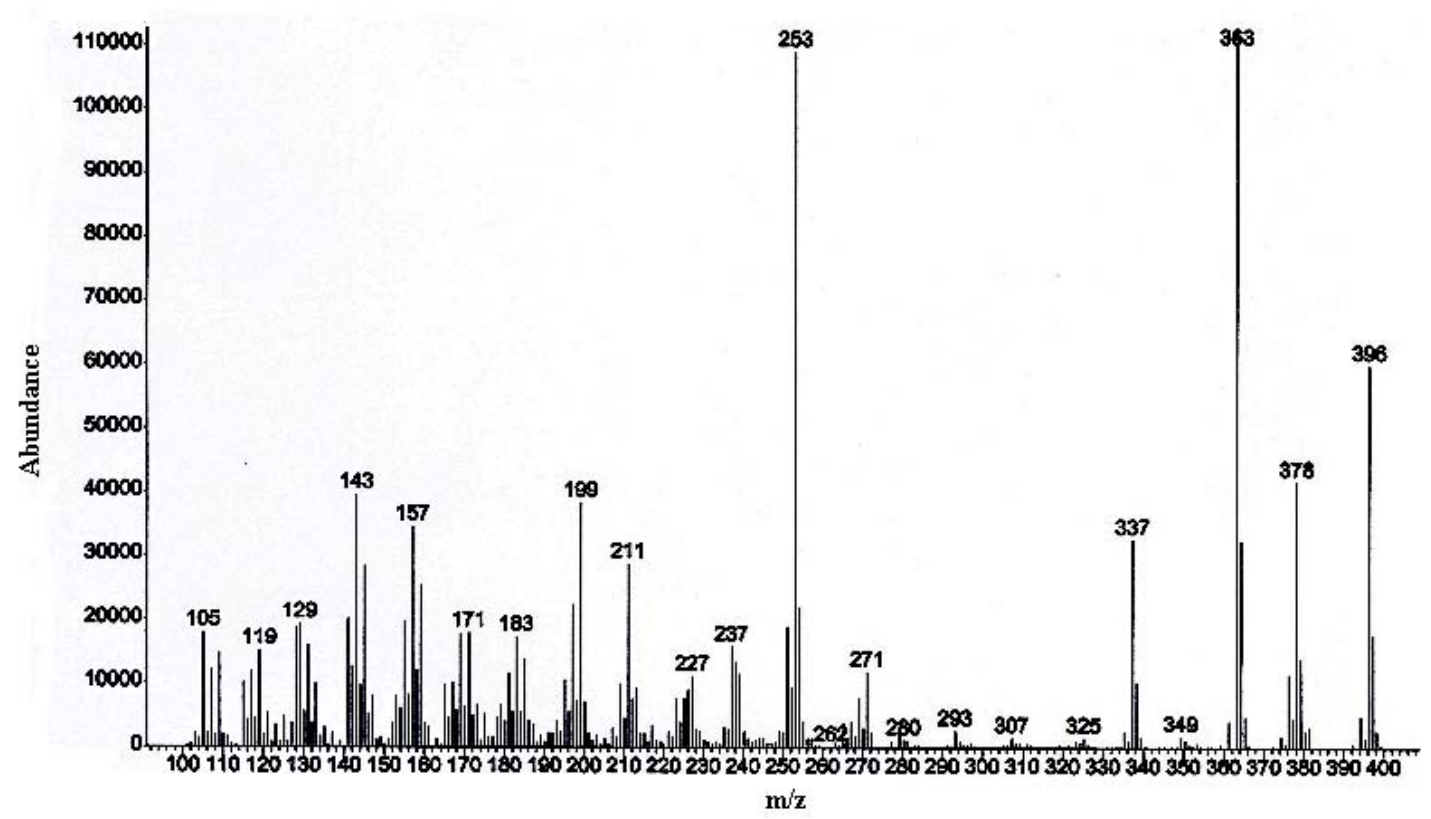

Figure 5b. Chromatogram of $17.5 \mu^{-1} g^{-1}$ ergosterol in P. ostreatus grown on barley.

The peaks of ergosterol were identified on the basis of retention times and spectral characteristics as compared to those of standard materials. The concentration of ergosterol samples $\left(\mu \mathrm{g} \mathrm{g}^{-1}\right)$ were calculated (Eqs. (2) and (3)) as:

Calibration Std.:

Calibration Factor $=\frac{\text { Area Counts of std. ergosterol }}{\text { Concentration of std. ergosterol }(\mu g)}$

For Sample:

$\frac{\text { Area Count of ergosterol sample }}{C F} \times \frac{\text { Volume of extract }(m L)}{\text { Mass of sample }(g)}=\frac{\mu g}{g}$ 


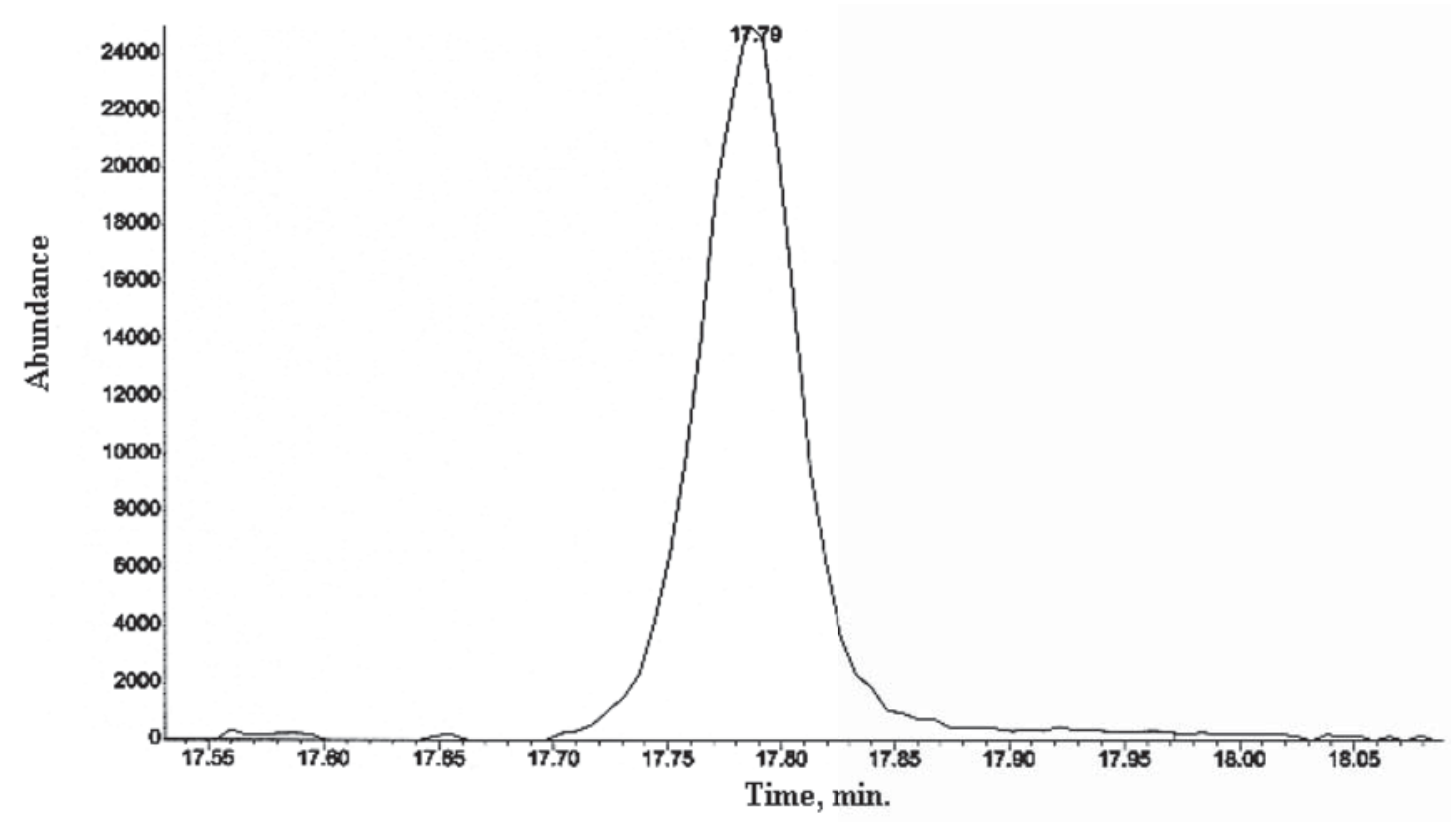

Figure 6a. MS chromatogram of ergosterol by EEM in P. ostreatus grown on barley, m/z 396.

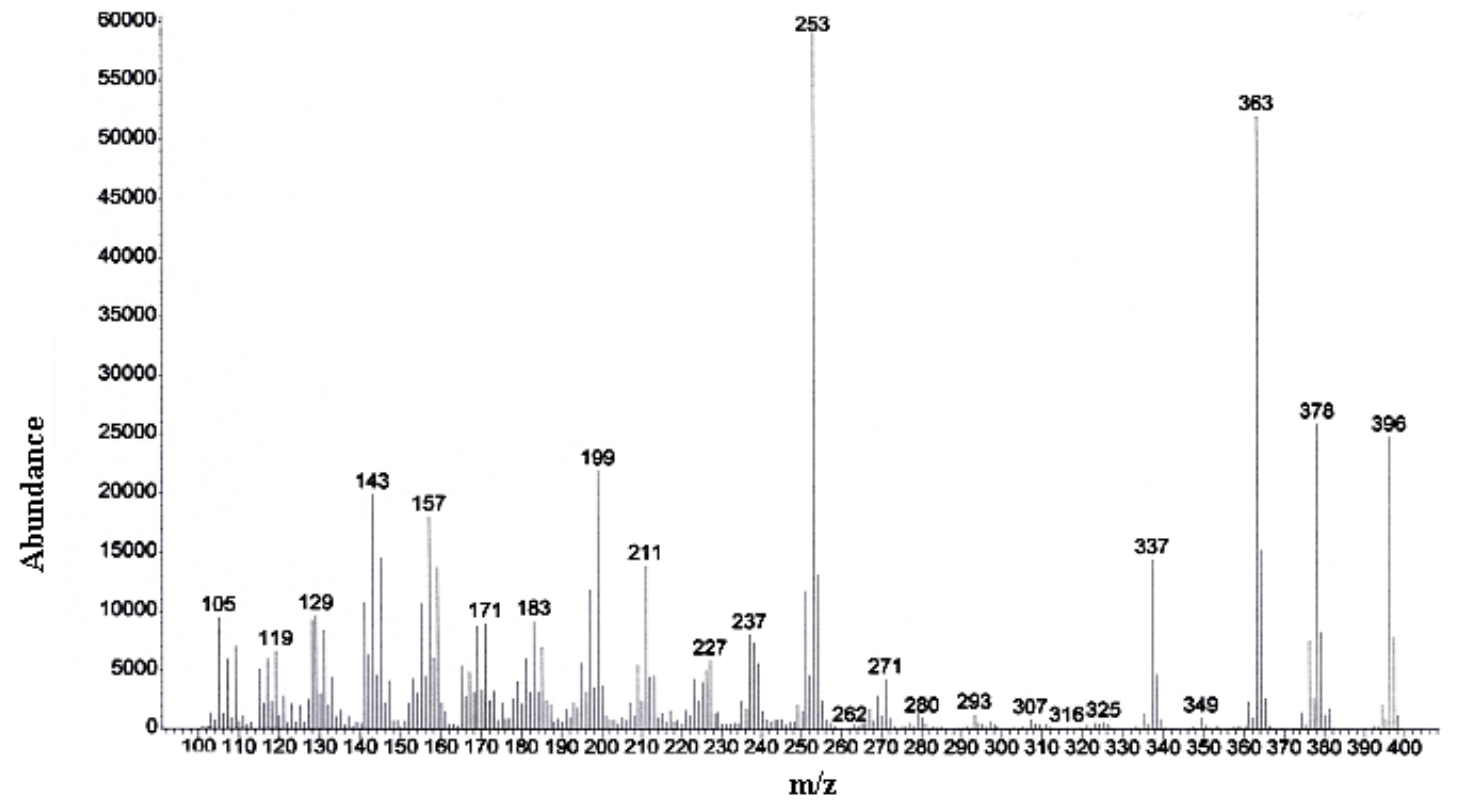

Figure 6b. Chromatogram of $39.94 \mu \mathrm{gg}^{-1}$ ergosterol in $P$. ostreatus grown on barley.

This method is useful for measuring the PAHs and ergosterol with great precision and accuracy without any hindrance. The extracts of the extractions for the samples which include sediments such as: pure fungi plus sediment and fungi (grown on barley) plus sediment, sterols were detected only after acetylation of the reaction mixture. This is because, acetylation was necessary to separate sterols from contaminants such as PAHs, these contaminants act as hindrance in analyzing extracts on GC-MS. 


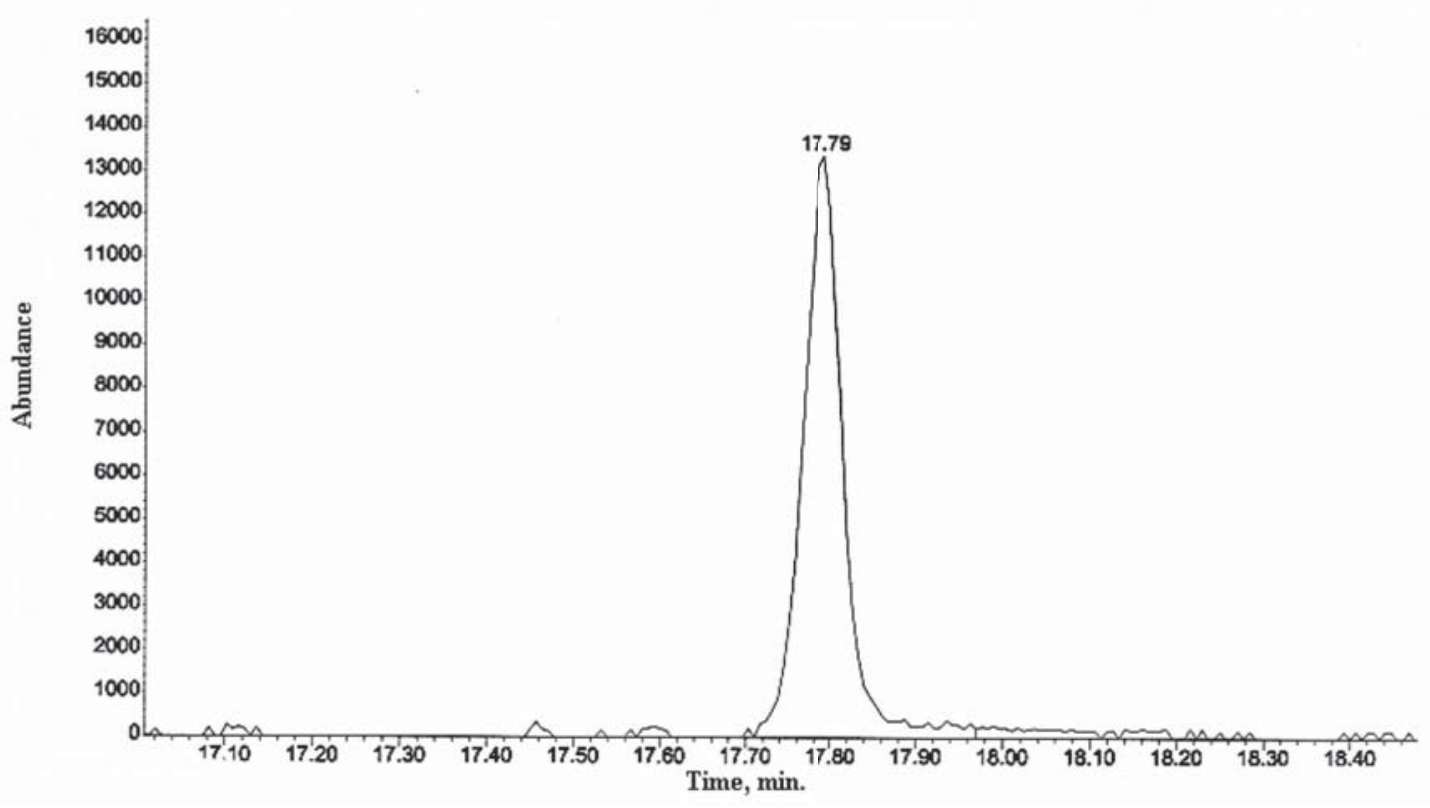

Figure 7a. MS chromatogram of ergosterol by EEM in P. ostreatus grown on barley, m/z 396 .

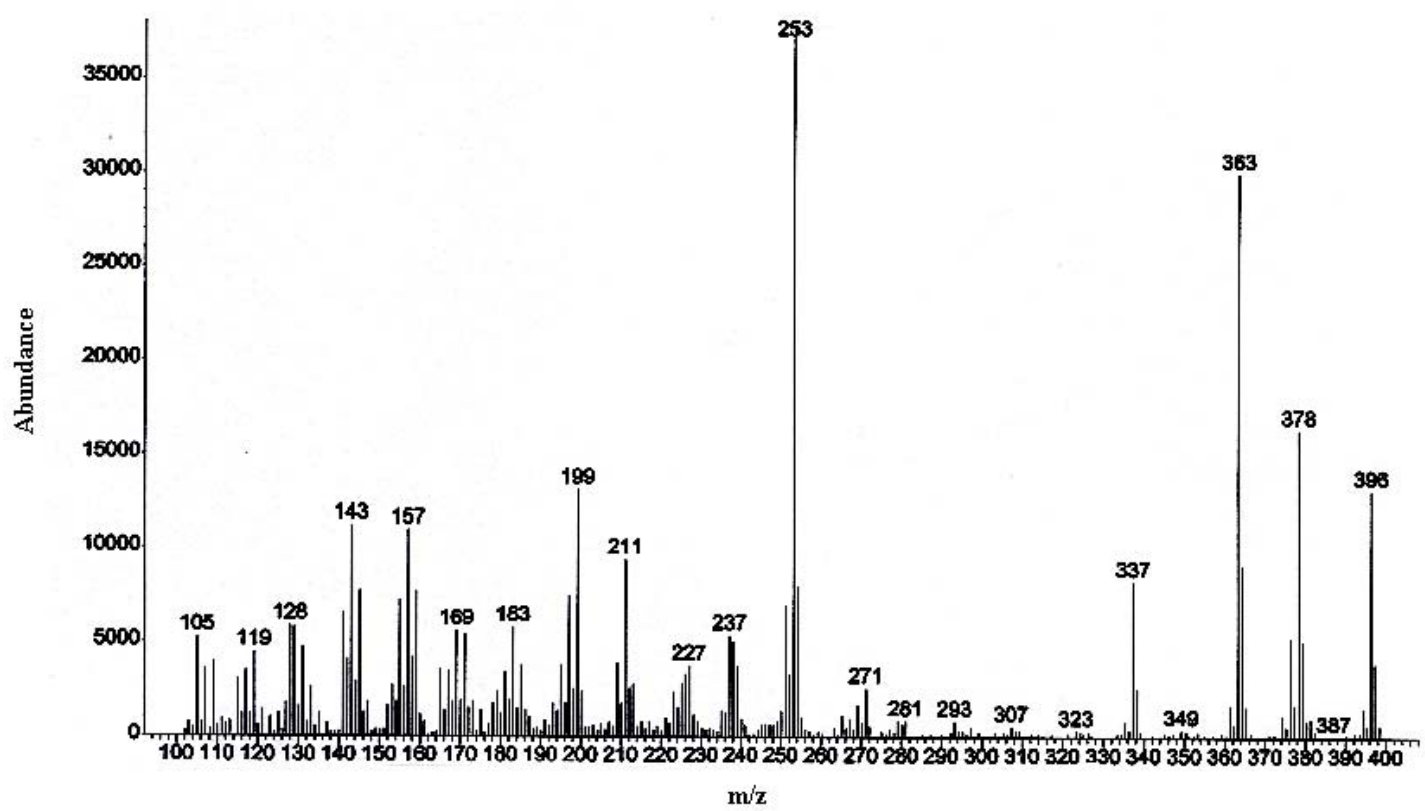

Figure 7b. Chromatogram of $21.58 \mu \mathrm{gg}^{-1}$ ergosterol in P. ostreatus grown on barley.

\section{Comparison of Lipid Extraction Method and Ergosterol Extraction Method:}

The solutes obtained from the extractions of the samples from these two methods were both analyzed by GCMS. Eleven PAHs were detected in Mahoning River sediment using the modified Fang and Findlay lipid extraction procedure. A total of sixteen PAHs were detected by ergosterol extraction method (Figure 8). Ergosterol and cholesterol were also extracted and detected from this method. By Ergosterol Extraction Method both PAHs and sterols were detected with great efficiency and ease. It is also less time-consuming and does not require many solvents. Therefore, the Ergosterol Extraction Method is the most effective method both qualitatively and quantitatively for simultaneous analysis of PAHs and ergosterol. 


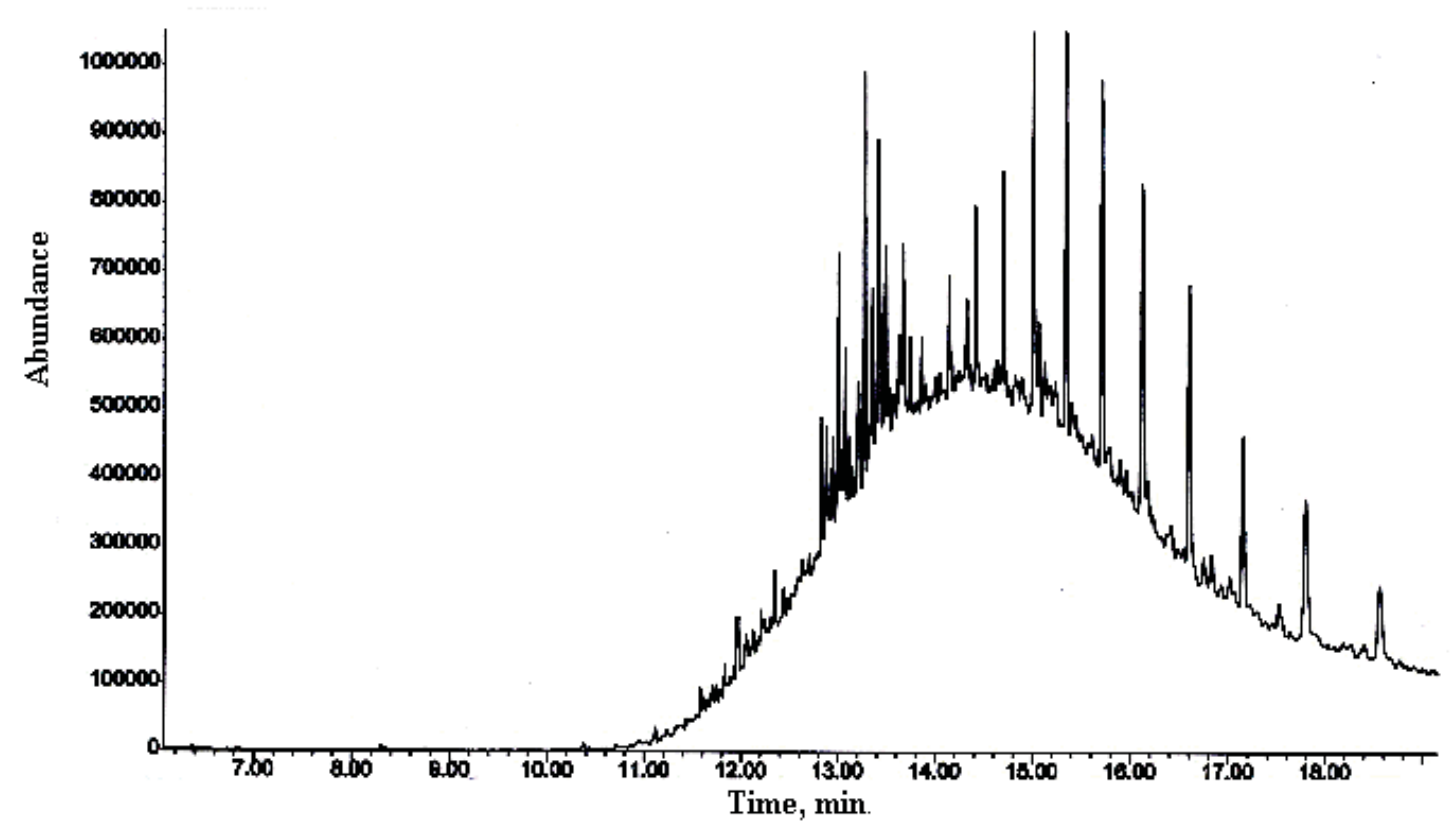

Figure 8a. MS chromatogram PAHs from sediment sample by EEM, m/z 119, 128, 136, 145, 159, 171, 197, 284, 270, 302.

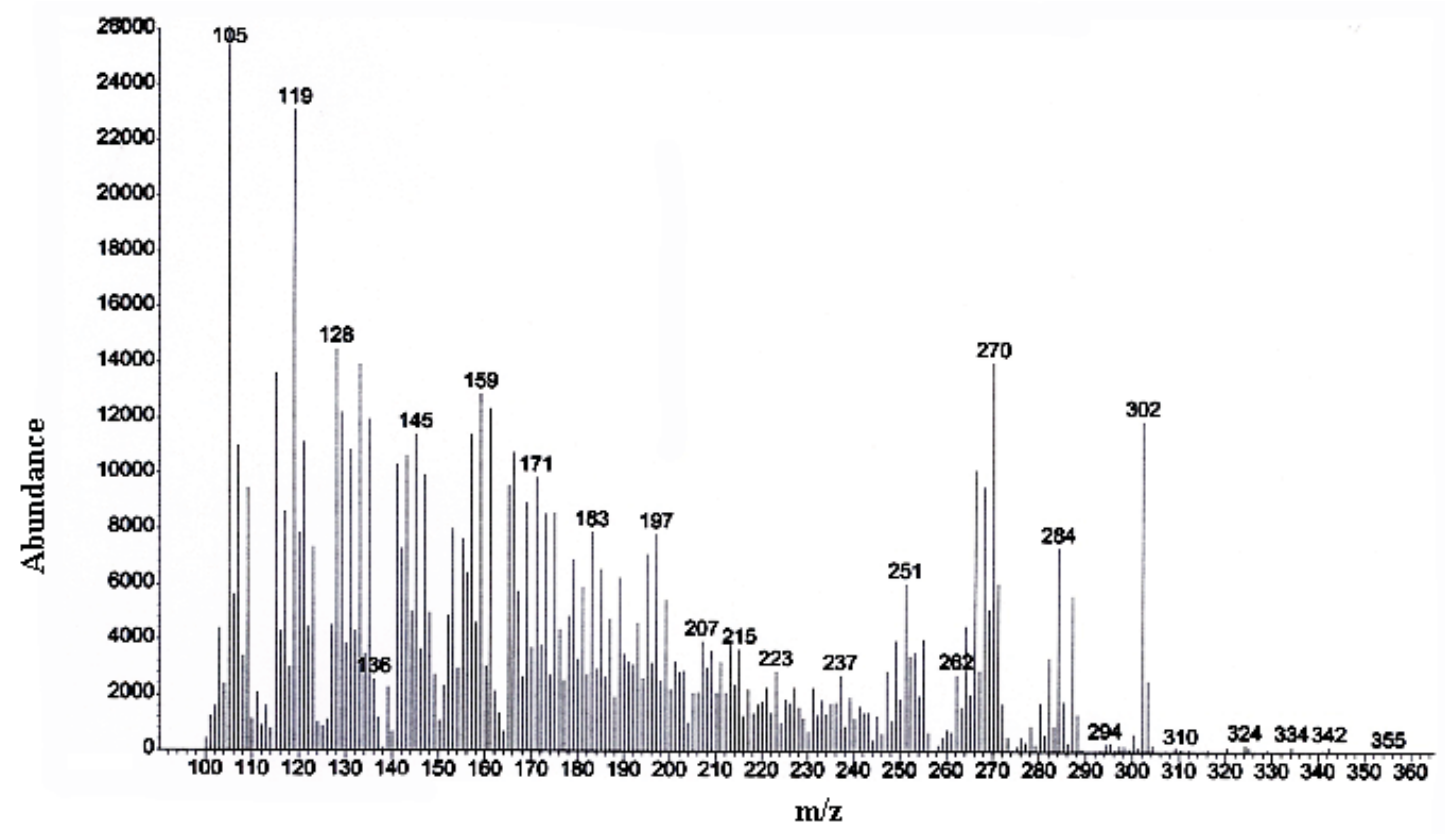

Figure 8b. Chromatogram of PAHs from sediment sample by EEM.

\section{Conclusions}

In conclusion, an efficient and high yielding Ergosterol Extraction Method was developed by which more PAHs were obtained than with the usual Lipid Extraction Method. Sediments were inoculated with P.ostreatus. Ergosterol Extraction Method was used as an effective tool for the extraction of ergosterol from P.ostreatus and bioremediation of contaminated sediment from PAHs by adding P.ostreatus. The detection of good amounts of ergosterol in white rot fungi, P.ostreatus confirms the fact that it acts as bioindicator of fungi. The growth of fungal mycelia can be increased by inoculating the treatment with a nitrogen source which serves as nutrients for fungi. EEM was particularly adapted 
for studying ergosterol in various treatments and matrixes. EEM was used to quantitate and analyze the biodegradation of PAHs and the change in the amount of ergosterol in P.ostreatus at different treatments, at different times such as $0 d$ and $21 \mathrm{~d}$. For ergosterol extraction, different treatments were set up with various amendments for at least three runs and every extraction was done in triplicate at two different times for these runs.

Degradation of PAHs should be seen in the future work by EEM at times $0 d$ and $21 d$, also the change in the amounts of ergosterol must be seen at these time periods. For triplicate incubations, sediments from the same site and the same spot sampled at same time are recommended. Pleurotus ostreatus was found to be effective in removing PAHs from the contaminated sediment.

\section{Acknowledgments}

Use of Research Core Facilities and financial support were made possible by the Department of Geological and Environmental Sciences, Youngstown State University, Ohio. The author (MO) is thankful to the Department for Teaching Assistantship.

\section{References}

1. Ohio Environmental Protection Agency, Biological and water quality study of the Mahoning River Basin, OEPA Technical Report. 1996, MAS/1995-12-14, pp. 1-249.

2. $\quad$ Perera, F.P.; Rauh, V.; Whyatt, R.M.; Tsai, W.Y.; Tang, D.; Diaz, D.; Hoepner, L.; Barr, D.; Tu, Y.H.; Camann, D.; Kinney, P. Effect of Prenatal Exposure to Airborne Polycyclic Aromatic Hydrocarbons on Neurodevelopment in the First 3 Years of Life among Inner-City Children. Environmental Health Perspective: Children's Health, 2006, 114(8), pp. 1287-1292.

3. Luch, A. The Carcinogenic Effects of Polycyclic Aromatic Hydrocarbons. London: Imperial College Press. 2005, ISBN 1-86094-417-5, 516 p.

4. Spink, D.C.; Wu, S.J.; Skink, B.C.; Hussain, M.M.; Vakharia,D.D.; Pentecost, B.T.; Kaminsky, L.S. Induction of CYP1A1 and CYP1B1 by benzo(k)fluoranthene and benzo(a)pyrene in T-47D human breast cancer cells: Roles of PAH interactions and PAH metabolites. Toxicology and Applied Pharmacology, 2008, 226(3), pp. 213-224.

5. Zhang, C.; Li, X.; Li, P.; Lin, X.; Li, Q.; Gong, Z. Biodegradation of aged polycyclic aromatic hydrocarbons (PAHs) by microbial consortia in soil and slurry phases. Journal of Hazardous Materials, 2008, 150(1), pp. 21-26.

6. Bixian, M.; Jiamo, F.; Gan, Z.; Zheng,L.; Yushun, M.; Guoying,S.; Xingmin, W. Polycyclic aromatic hydrocarbons in sediments from the Pearl river and estuary, China: spatial and temporal distribution and sources. Applied Geochemistry, 2001, 16(11-12), pp. 1429-1445.

7. Kanaly, R.A.; Harayama, S. Biodegradation of high-molecular-weight polycyclic aromatic hydrocarbons by bacteria. Journal of Bacteriology, 2000, 182(8), pp. 2059-2067.

8. King, A.J.; Readman, J.W.; Zhou, J.L. Determination of polycyclic aromatic hydrocarbons in water by solid-phase microextraction-gas chromatography-mass spectrometry. Analytica Chimica Acta, 523(2), 2004. pp. 259-267.

9. Oren, A.; Aizenshtat, Z.; Chefetz, B. Persistent organic pollutants and sedimentary organic matter properties: A case study in the Kishon River, Israel. Environmental pollution, 2006, 141(2), pp. 265-274.

10. Field, J. A.; Jong, E. D.; Gumersindo, F. C.; Jan, A. M.; De, B. Biodegradation of polycyclic aromatic hydrocarbons by new isolates of white rot fungi. Applied Environmental Microbiology, 1992, 58(7), pp. 2219-2226.

11. Cerniglia, C.E. Biodegradation of polycyclic aromatic hydrocarbons. Biodegradation, 1992, 3, pp. 351-368.

12. Javitt, N.B. Bile acid synthesis from cholesterol: regulatory and auxiliary pathways. FASEB Journal, 1994, 8(15), pp.1308-11.

13. Fang, J.; Findlay, R.H. The use of a classic lipid extraction method for simultaneous recovery of organic pollutants and microbial lipids from sediments. Journal of Microbiological Methods, 1996, 27(1), pp. 63-71.

14. Tardieu, D.; Bailly, J.D.; Bernard, G.; Guerre, P. Comparison of two extraction methods for ergosterol determination in vegetal feeds. Revue de Medicine Veterinaire, 2007, 158(8-9), pp. 442-446.

15. Headley, J.V.; Peru, K.M.; Verma, B.; Robarts, R.D. Mass spectrometric determination of ergosterol in a prairie natural wetland. Journal of Chromatography A, 2002, 958(1-2), pp. 149-156.

16. Axelsson, B.S.; Saraf, A.; Larsson, L. Determination of Ergosterol in organic dust by gas chromatography-mass spectrometry, Journal of Chromatography B, 666, 1995, pp. 77-84.

17. Parsi, Z.; Gorecki, T. Determination of ergosterol as an indicator of fungal biomass in various samples using nondiscriminating flash pyrolysis. Journal of Chromatography A, 2006, 1130(1), pp. 145-150.

18. Stahl, P. D., Parkin, T. B. Relationship of soil ergosterol concentration and fungal biomass. Soil Biology and Biochemistry, 1996, 28, pp. 847-855.

19. Yateem, A.; Balba, M.T.; Al-Awadhi, N. El-Nawawy, A.S. White rot fungi and their role in remediating oil contaminated soil. Environmental International, 1998, 24(1), pp. 181-187. 
20. Dietrich, D.; Lamar, R. Selective Medium for Isolating Phanerochaete chrysosporium from Soil. Applied and Environmental Microbiology, 1990, 56, pp. 3088-3092.

21. Brodie, E.; Edwards, S.; Clipson, N. Soil fungal community structure in a temperate upland grassland soil. FEMS Microbiology Ecology, 2003, 45(2), pp. 105-114.

22. Padgett, D.E.; Posey, M.H. An evaluation of the efficiencies of several ergosterol extraction techniques. Mycological Research, 1993, 97, pp. 1476-1480. 